\title{
Erratum to: Consistent Paradigm of the Spectra Decomposition into Independent Resonance Lines
}

\author{
K. M. Salikhov ${ }^{1}$
}

Published online: 8 July 2017

(C) Springer-Verlag GmbH Austria 2017

\section{Erratum to: Appl Magn Reson (2016) \\ 47:1207-1227 \\ DOI 10.1007/s00723-016-0823-3}

In the original article, Fig. 5 is published incorrectly. The correct Fig. 5 is given below.

The online version of the original article can be found under doi:10.1007/s00723-016-0823-3.

K. M. Salikhov

salikhov@kfti.knc.ru

1 Zavoisky Physical-Technical Institute, Russian Academy of Sciences, Sibirsky Trakt 10/7, Kazan 420029, Russia 

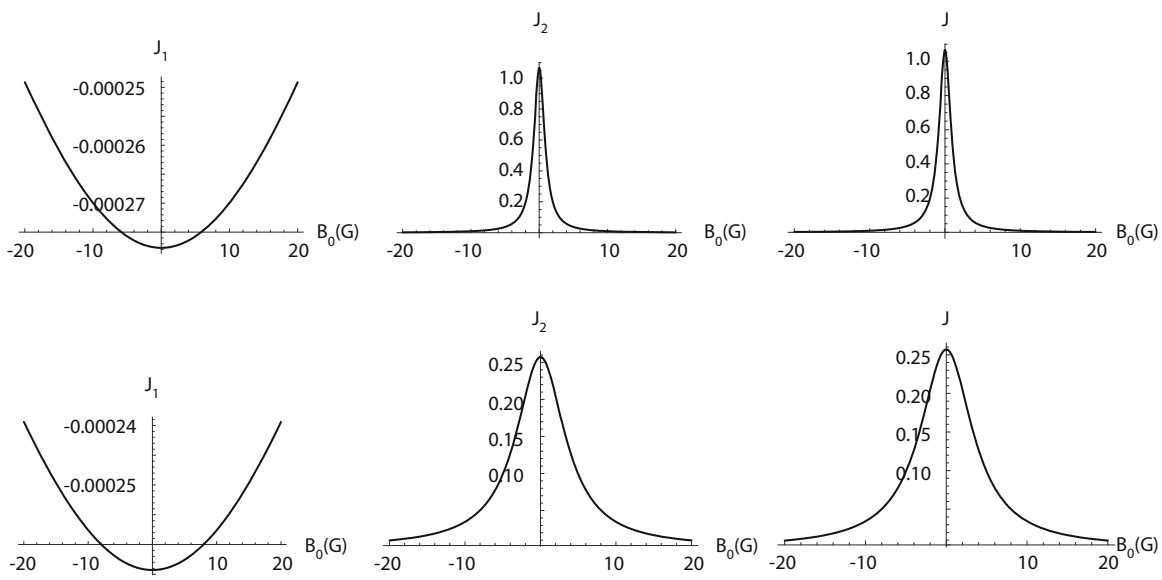

Fig. 5 Contributions of the two collective independent modes to the EPR spectrum (left-hand and middle columns), the total EPR spectrum (right-hand column): spin exchange case, $V=30 \mathrm{G}, W=V$, $a=15 \mathrm{G}$ (top row); both, spin exchange and dipolar, contributions operating case, $V=30 \mathrm{G}$, $W=33 \mathrm{G}, a=15 \mathrm{G}$ (bottom row) 